\title{
A STOCHASTIC ANALYSIS OF THE MAINTENANCE BEHAVIOUR OF SKYLARKS
}

\author{
by
}

JUAN D. DELIUS ${ }^{1}{ }^{2}$ )

\section{INTRODUCTION}

This paper, which is one of a series dealing with the behaviour and ecology of the Skylark Alauda arvensis (Delius, 1963, 1965) has a twofold aim. It describes, along the usual ethological lines, the maintenance behaviour of this bird. Although often neglected, non reproductive behaviour has lately attracted some attention perhaps mainly because of the frequent and seemingly irrelevant appearance some of it makes in the context of reproductive behaviour (e.g., van IERSEL \& BoL, 1958), but also because it challenges an explanation in being recognisably organised (e.g., Ewer, 1967), or because of its significance in comparative studies (e.g., McKinnry, I965). At the same time, however, the paper is an attempt of applying an analytical procedure which seems potentially useful for behavioural studies. While the desirability of quantitative behaviour descriptions has long been recognized, a confusing variety of descriptive frameworks have been used. Spectral functions would seem eminently suited to replace some of this variety since they usefully typify a wide variety of stochastic processes (BARTLETT, 1966). Over the last years techniques have been developed which make it possible to derive such for behavioural data. They are these techniques I am attempting to explore, although because of shortcomings in the data collected long before this analysis was envisaged, their application will remain in-

I) I wish to thank Professor N. Tinbergen, F.R.S. for supervising the fieldwork, Sir W. Pennmaton Ramsden Bart. and the Cumberland County Council for permission to work in Ravenglass. Mrs E. Templeton for computing advice, Dr R. Dawkins for providing a computer program used early in this sttidy and my wife for preparing much of the data and manuscript. The work was supported by grants from the U.S. Air Force Office of Scientific Research through the European Office of Aerospace Research, and the Science Research Council.

2) Present address: Dept of Neurosciences, UCSD, La Jolla, Calif. 92037, U.S.A. 
complete and imperfect. However, it is hoped that it may stimulate further and more consequent work.

\section{OBSERVATION METHODS}

The data were obtained from behaviour observations made on individually marked Skylarks of a population at Ravenglass Gullery in Cumberland, England, $54^{\circ} 21^{\prime} \mathrm{N} 3^{\circ} 25^{\prime} \mathrm{W}$. They were watched with the aid of $10 \times 5^{\circ}$ binoculars, mounted with a ball-joint on a tripod. The territories of the Skylarks were located in dune valleys with scarce vegetation and so individual birds could be followed for virtually unlimited periods, interrupted only by rare absences from the territory, ustually lasting less than a minute, or by bouts of incubation. When they were observed at the nest from a hide on the other hand, it was not possible to follow them when they were off the nest. In this way records of no less than 30 minutes and up to 5 hours (average 2 hours) were obtained from individual birds. Some 200 hours of observation are available of which some $\mathbf{2} 20$ consist of virtually uninterrupted periods. These provided the bulk of the data used in this study. Additionally more casual notes were made over some I 5 months of field work, spread over 4 breeding seasons. The behaviour records were attempts to note all observable behaviour with a concurrent time basis. They mainly consist of strings of symbols, standing for the diverse behaviour patterns and their variations interspersed with timing notes at variable intervals between 2 and 3 minutes. Since however the durations of several behaviour patterns were fairly constant, it was possible to allocate behavioural events to particular one-minute-intervals with reasonable confidence.

The records relevant to this study were transcribed on punched tape so that all further processing could be done with a KDF 9 digital computer using programs especially written for the purpose by the author $\mathbf{1}$ ).

\section{ANALYTICAL METHODS}

When attempting to describe the relationships between the input and the output variables of a linear system, one of the procedures used in system analysis is frequency analysis (Milsum, I966). This consists in driving the input with a sinewave of a given amplitude and varying its frequency from ideally zero to infinite, and measuring the output in terms of amplitude and phase relations to the input. From this information the transfer functions of

I) A comprehensive program deck for random event series analysis is now available for the IBM 360 (LEWIS, 1967). 
the system can be derived mathematically. This enables one to predict the output of the system for virtually any input signal. Often it is simpler and equally convenient to present the results of the frequency analysis in a more direct way as frequency response functions (Bode plots or Nyquist diagrams, Fig. I).
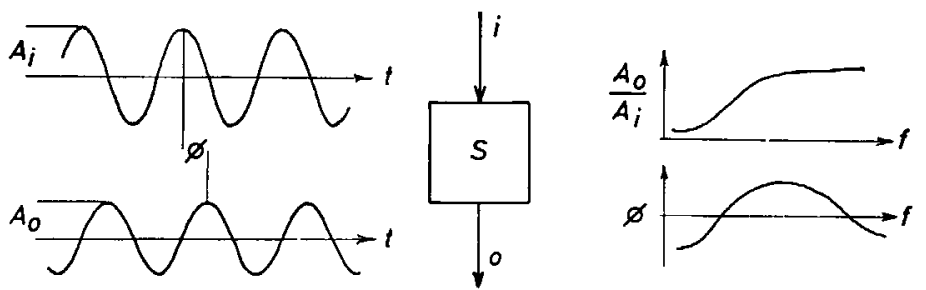

Fig. I. Obtaining the frequency response of a linear system. The frequency of the input signal is varied systematically.

In random signal analysis (Bendat \& Piersol, r966) use is made of the same basic principle except that the input is a random continuous variable, usually not under control of the experimenter. The random signal can be resolved through a procedure known as generalized harmonic analysis into sinewaves of different frequencies and amplitudes. Similarly the output of the system can be resolved into sinusoids bearing specified amplitude and phase relationships with the input.

In practice this involves obtaining the autocorrelation function of the input variable and the crosscorrelation function between it and the output signal. The first is obtained by correlating the amplitude of each point of the input signal with the amplitudes of corresponding points of the same signal after a given time interval or lag with reference to the first points. The correlation coefficients are a function of these intervals or lags (Fig. 2). The cross-


Fig. 2. Obtaining the autocorrelation function of a signal. The lag 1 is varied systematically. The correlogram from which the correlation coefficient is derived is shown for a given lag. 
correlation function is similarly obtained, but here the amplitudes of the input variables are correlated with the lagged amplitudes of the output signal (Fig. 3). While the autocorrelation functions are equivalent for positive and negative lag values, the crosscorrelation functions are usually not symmetrical and must therefore be computed for negative and positive lags.

These functions can be transformed purely mathematically into the power spectrum and the crosspower spectrum respectively, where the crosspower spectrum is a complex function giving both the power and phase of the output relative to the input $\mathbf{1}$ ). From these functions it is again possible to derive the transfer function of the system under the assumption of linearity, but often it is equally convenient to present the data in terms of frequency response functions.
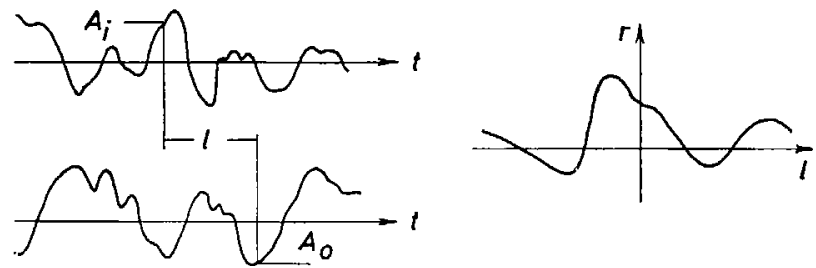

Fig. 3. Obtaining the crosscorrelation function betwecn a pair of signals. The lag 1 is varied systematically.

As we will see later some behavioural data can not easily be treated as continuous random signals and therefore use is made of a further and related type of analysis known as random event series analysis (Cox \& LewIS, 1966). This is useful for cases in which the input and output signals can be considered as a series of dimensionless points in time.

Variables of such nature can be viewed in two ways: as a count process
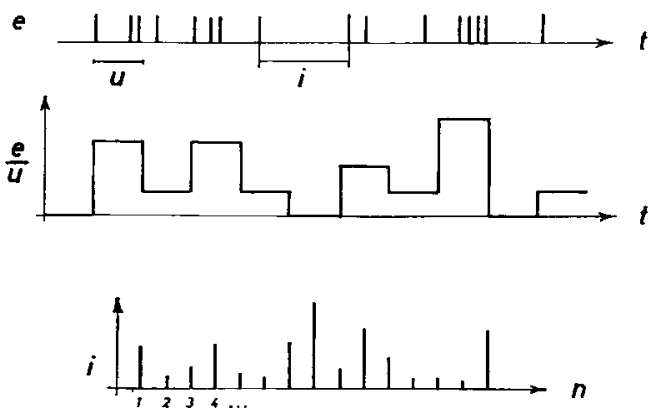

Fig. 4. A series of events viewed as a count process $e / u(t)$ and as an interval process $i(n)$. The arbitrary time unit $u$ is chosen depending on convenience.

I) A useful introduction to this methods is given by WALTER (1963). 
where the variable is the frequency of occurrence of the event in some arbitrary time unit as a function of time, or as interval processes where the variable is the interval duration between events as a function of the event sequence and not of time (Fig. 4). While the two processes are equivalent if all the higher order properties of the process can be established, this is as yet impracticable and therefore non-equivalent information can be gained from considering both processes. For the count process this presents little difficulty since it can be treated much like the continuous signal case, in other words, auto- and crosscorrelation and their derivations can be obtained by analogous procedures. With the interval process no difficulty exists for the autocorrelation and its power-spectrum transformation, but no general techniques have as yet been proposed for dealing with crosscorrelations and -spectra $\mathbf{1}$ ).

\section{BEHAVIOUR AS SIGNALS}

Treating behaviour as variables or signals requires some comment. Generally ethologists have considered behaviour as representable by streams of qualitatively discrete, invariant patterns of movement or vocalisation, although it is recognized that animals may show complexly varying activities. Graded pattern components may, for example, occur in various combinations giving a scale of patterns which can not reasonably be divided into qualitative discrete units.

The recognition of behaviour patterns by the observer involve subjective decisions and this is an issue which will need considerable attention in future if advanced techniques of analysis are to be applied with any validity. An equally serious source of error is that the observer may miss to record the occurrence of events because of inattention.

In this study we will only deal with behaviour patterns which can be considered qualitatively discrete and which are judged to be clearly differentiable by the observer, as well as obvious enough as not to pass easily unnoticed.

Several modes of occurrence of qualitatively discrete types of behaviour can be recognized (Fig. 5). Some patterns can with reasonable approximation be considered true point events; in other words, their duration is relatively invariant and very small compared with the inter-event intervals. All patterns treated in this paper are for all purposes of this type. Other patterns may however have a definite duration which is often variable and cannot be

1) A lucid review of this field is given by Perkel, Gerstern \& Moore, 1967. 
descriptively disregarded. Such signals can still be treated as point events if one deals with them as series of alternating on and off events and analytical techniques are available for coping with these alternating processes much in the same way as simple event processes (Cox \& LewIs, I966). A further type of behaviours are such which are shown with either discrete or continuous varying levels of intensity. These latter types could be treated as continuous random signals. Complex patterns as mentioned above may of
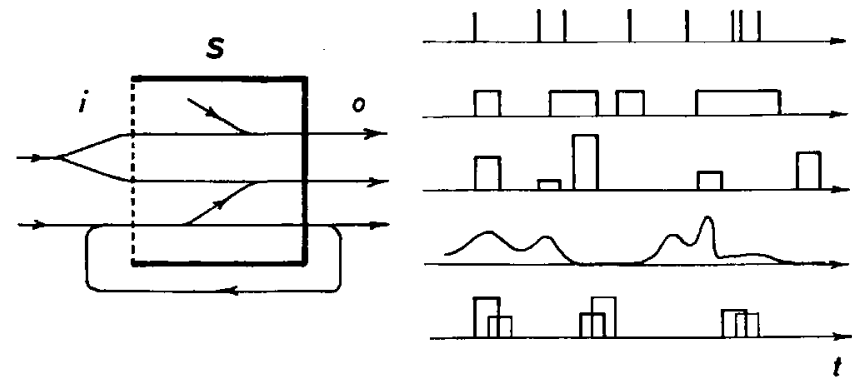

Fig. 5. An animal as a black box illustrating some of the causal links which could operate (left). Behaviour as signals illustrating some of the possible configurations right).

course be resolved into their components, ultimately perhaps in terms of contractions of single muscles and analysed separately ${ }^{1}$ ).

\section{ANIMALS AS SYSTEMS}

When an animal is studied with behavioural methods it can be considered as a "black box" with inputs consisting of streams of stimuli inpinging on it and outputs emmited by it as series of behaviour patterns (Fig. 5). The properties of such a black box can be determined in several ways, for example by studying one by one the various input/output relationships, perhaps using frequency analysis, this requiring an accurate operational stimulus control, or using random signal analysis on the naturally occuring random or near random fluctuation of stimuli. A difficulty here is that several inputs may be affecting simultaneously a given output, but random signal analysis offers techniques analogous to partial correlation and regression coefficient which are capable of unravelling the extent to which the different inputs contribute.

A more serious practical difficulty is that of having to record simulta-

1) This also may well be a way of objectivizing behaviour observation since myogram telemetry of fully instrumented animals seems technically foreseeable (Ko \& NeUmaN, I967). 
neously not only the behaviour of an animal, but also the stimuli likely to affect it. Even under nearly ideal conditions this is difficult, but under the field conditions of the present study it was impossible and therefore our analysis is restricted to the output of the system. The black box under these conditions is in fact an open ended one, that is the properties which may be found for it may either be due to the actual organisation of the animal, or to causal concatenations of the inputs arising outside of it, i.e. in the environment. This restriction of course applies to many ethological studies, but its implications have rarely been emphasized. Correlations between two behavioural outputs may under these conditions therefore either reflect a physiological linkage in the animal's system, or only a physical relationship in the environment between the stimuli which control independently, as far as the animal's system is concerned, the two behaviours. Apart from that, and more generally, there is also the possibility that stimuli are consequences of the animal's own behaviour, i.e. of correlations between outputs and inputs in that causal order which maintain causal loops external to the system itself. And finally the possibility of signal generation within the system itself, either random as system noise or periodic automatic rhythms both being stimulus sources not directly accessible to observation.

A serious restriction on the application of random signal or event analysis is the requirement that input and output variables, and thereby the system, must be stationary in their statistical properties, i.e. not change with time. On a priori ground this condition is unlikely to be met in animals. Certain non-stationarity, as for example trends or periodicities in the means of variables can be dealt with in a fairly simple way, but changes in higher order properties are somewhat more difficult to cater for (BENDAT \& Piersol, ig66).

While system non-linearity does not affect the analysis itself the interpretations of the results depend to a certain degree by whether linearity or what type of non-linearity does apply and therefore efforts should be made to determine them. Some analytical techniques appear to be available for this (CAughey, 1963). All the same it has been argued by Tukey (I961) that as long as these sources of errors are kept in mind, random signal analysis may still yield more information about the system than any other type of analysis. Just as verbal descriptions are no more than precursors to such things as transition and correlation matrices, which by the way can also be affected by non-linearity and non-stationarity, random signal analysis is only a step towards more sophisticated descriptions, which will once suitable mathematical procedures have been developed, take into account non-linearity and non-stationariness. It must, however, be admitted that very 
radical departures from these two assumptions may detract considerably from any gain of information, but then, it will be usually possible to detect such extremes.

\section{BEHAVIOUR DESCRIPTION}

Qualitative descriptions of all patterns which are treated quantitatively in the remainder of this paper are given in this section. For the sake of
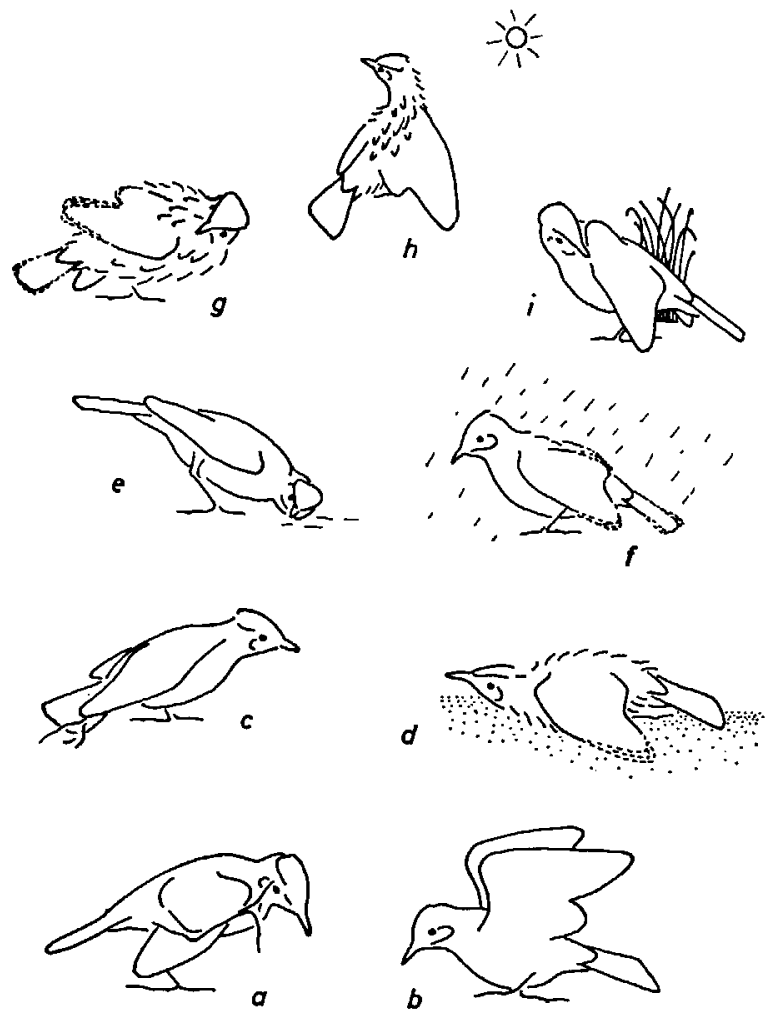

Fig. 6. Some of the comfort behaviour patterns of the Skylark. (a) Scratching, (b) Both wing stretch, (c) Wing and leg stretch, (d) Dustbathing, (e) Bill and head wiping. (f) Rainbathing, (g) Bodyshake, (i) Preening, (h) Sun bathing.

completeness and for comparative purposes, however, I discuss a number of patterns belonging functionally to maintenance behaviour, even when because of the small amount of data available on them they will not be dealt with further.

The terminology used for the comfort behaviour follows closely that of 
McKinNEY (1965), but of course this does not imply that I necessarily consider the comfort patterns of Skylarks homologous with those of the Anatidae.

Bodyshake (Fig. 6g). The bird fluffs its back, waggles its tail side to side (always?), holds its wings out slightly and shuffles them rapidly from side to side, while fluffing the rest of the plumage. The wing movements often communicate to the rest of the body, which then occilates slightly along its longitudinal axis. Finally after a just perceptible pause, the head usually follows suit with a Headshake, in which it is rotated around its neck axis from side to side over more than 180 degrees. The bodyshake sequence lasts about 5 secs and ends with a re-settling of wings. Headshaking sometimes occurs on its own. It is possible that Skylarks have a movement analogous to the duck's headflicking, but I found it impossible to distinguish it in the field from the headshaking as shown in the bodyshaking. If present, it is characterised by an up and down, or nodding, head movement and appears to be effective in removing unwanted objects from the mouth. Tailwagging also occurred on its own and although it was only observed on a few occasions it may be more frequent, only that it is a movement which can easily pass unobserved. It consists of a side to side movement of the tail without spreading it. Fluffing, another component of bodyshaking, could often be seen independent of it, but since ruffling of the plumage also accompanies sexual and agonistic postures it was difficult to decide whether instances of it may not have been low intensity performances of these patterns. In a less transient form it probably serves thermoregulatory functions (see below). Typically, fluffing begun with the back feathers and spread then to the rest of the plumage, but a good deal of variation in patterning and intensity occurred and it was not possible to record it in any consistent way. Usually it was a brief episode lasting only a second or two, but occasionally it was quite prolonged, then perhaps as a thermoregulatory response. Another shaking movement whose occurrence however could not be established with certainty since in the few instances it was seen it might have been accidental, was Footshaking, where a leg was somewhat lifted and kicking movements were performed with it.

Preening (Fig. 6i). With fast movements the feathers are drawn through the beak. The following movements could be distinguished depending on the body area preened. Neck, breast and belly preening requiring no description. Inside wing preening, for which the bird droops the wing and approaches from above, preening either the wing inside or the flank. Wingbow and primaries were preened approaching from underneath while holding the wing out and forward. Wingface preening, involving the outer surface of the 
wing, ustually without moving it from its normal position. Back, tailcovers and tail preening do not need any description. After preening proper sequences it seemed possible to distinguish — though not with certainty - sequences of oiling where the birds apart from reaching the oil glands with the beak seems to draw the feathers more rapidly than during preening proper and also showed a rubbing of the side of the head over the wings and back. The number of single movements composing a preening bout varied considerably and so did the duration as well as the sequence of movements, but this will be discussed later. For the purpose of most of the following sections however, each preening bout was considered to be a single event independently of its structure and duration. Head scratching (Fig. 6a). One foot is brought forward and up over the wing, which is drooped a bit, the head is bent towards the foot and then any part of the head may be scratched with repetitive movements. This activity lasts a few seconds. Occasionally the birds seem to loose balance and may briefly pause, but I have disregarded these interruptions for the purpose of this paper. Bill- and headwiping (Fig. 6e). Either the beak or the face are held against the ground and wiped with stroking side to side movements. Footpecking. The birds bend down the head and peck at their feet without lifting them, thereby removing small objects sticking to them. This pattern was particularly noticeable in birds which had just been ringed.

Both wings stretch (Fig. 6b). The bird stretches slightly forward, lifts both its wings up and above its back so that bows and tips come close together, holding them there for a second or two. It was repeatedly noticed that one wing lagged appreciably behind the other during the raising and folding phases. In a few occasions, always concerning females, these postures could not be distinguished clearly from a mild threat posture. Wing and leg stretch (Fig. 6c). The wing and leg of the same side are stretched out back and downwards and the tail is fanned to the same side. Occasionally it may have been that the tail or leg was not involved, but it was difficult to be completely sure about this. The duration of this act was again of the order of a few seconds and varied little.

Rain bathing (Fig. 6f). During fine drizzling rain and sometimes after heavy rain Skylarks show alternating side to side wing movements with these slightly held out at the carpal joints while the tips remain in the normal position. The tail is sometimes slightly spread and the plumage somewhat fluffed. These jerky scissoring movements can go on for minutes, while the Skylarks usually continue walking about and feeding. I never saw bathing in open water, although suitable pools were available. Sun bathing (Fif. 6h). The plumage is fully fluffed, one wing and some- 
times both are extended, the head and neck often stretched and bent sidewards, the bird remaining absolutely still up to 2 minutes or so, while it is positioned in such a way, as to be exposed maximally to the sun rays. Often it pants even though air temperature may be relatively low. Dust bathing (Fig. 6d). On a spot with loose sand the bird begins giving some scattering pecks at the ground and then squatts with the plumage fluffed, the wings drooping down to the ground, the tail fanned and depressed, scratches with the feet so that it pushes itself forward, then shakes the wings side to side, beating the ground with them - perhaps with one wing at the time - then scatters the sand with pecking and follows it by a similar sequence with an interval in which it may adopt a sun bathing-like attitude. This can go on for minutes at a time.

Now brief descriptions of some other maintenance activities will follow beginning with the locomotion patterns. Flying varied much depending on the context and the conditions. Most frequently it was of the typical passerine pattern, i.e. one in which a series of wingbeats alternate with ballistic paths with virtually closed wings, but sometimes it was of a hovering or a gliding type, or swoops with the wings half folded. For further descriptions of flight patterns used in posturing context see DeLius (I963). In the remainder of this paper I have disregarded all flight activities clearly connected with displays. Bouts of flying were usually of brief duration, not more than 5 secs. at a time, and its functional meaning was in most occasions unclear, although they may well have been directed at events which escaped the observer's attention. The impression was that they were very often an expression of the level of general activation. In this context Crest raising may be mentioned which appears to be similarly motivated and has been discussed in Delius (1963). Most of the Skylark's time is spent Walking, usually while feeding. Its speed can vary from fast running to slow motion creeping. Rarely they Iump, apparently as a startle response but hopping occurs commonly in courtship contexts (DeLrus, 1963).

The typical rest activities were Sleeping, only observed during night time, when the birds tucked their beak into the wing in sheltered clearings, except incubating females which sleep on their nests. Dozing, where the birds become inactive usually with the plumage somewhat fluffed, drawing intermittently the nicitating membranes over the eyes, usually over one eye at a time. Also clearly connected with sleep is Yazuning, where the mandibles are opened widely and the tongue is curled upwards. During apparent transitions between rest periods and activity bouts, episodes of Staring were shown, consisting of either monocular or more typically binocular fixation. They may be related to the staring down of other species 
(HARRISON,I965). All these latter patterns however could only be recorded reliably in incubating birds (DELIUS, I963).

Feeding is the most prominent activity Skylarks indulge in. It varied according to the type of diet they took and this depends on the season, progressing from grains to insects as spring advances. Much was just gathered but sometimes Skylarks would pull out tufts of moss or grass or would ease apart with repeated pecks clumps of marram grass. This Groundplucking is seen quite often as a displacement activity particularly in agonistic contexts and is then often not followed by any food intake. The same groundplucking however is also shown as incipient nestbuilding (see Delius, I963). They also quite effectively chased after insects on the wing. Once caught, insects were often subjected to very energetic shaking, it not being clear to what purpose. While feeding these to their young they showed the remarkable habit of laying aside their catch to pursue a new prey, then returning, of ten from several yards away to gather up the lot (ASHFORD, I9I5). The intensity of food gathering was quite noticeably variable, incubating females for example would search frantically when off the nest, interrupting the fast feeding with little other behaviour, while males would at the same time go about it leisurely. Drinking was never seen in the free ranging Skylarks but caged birds did so regularly, either by dipping the beak in the water and subsequently holding the head up, or by pecking off dew drops from the grass. Defecation. The lower abdomen was slightly projected outwards to produce usually very dry feces; often one had the impression that this pattern was precipitated in stress situations.

Respiration which under normal circumstances went on at the rate of 60 cycles a min also shows variations depending on the behaviour context and did not always seem clearly related to muscular effort. It would be slow and shallow when Skylarks froze because of overflying predators or rapid and deep when they caught sight of sexual partners or opponents. Thermo-regulation was achieved behaviourally by Fluffing and Panting, although these two patterns were also shown in posturing contexts, presumably not requiring such active temperature regulation. Regarding fluffing two types could be distinguished, one shown in cool weather in which a continuous body contour was maintained and another, shown in very warm weather in which the feathers were maximally abduced from the skin (MORrIS, I956). In very cold weather I noticed in a few occasions a small amplitude fast wing Shivering, possibly analogous to mammalian shivering (WEST, I965). 


\section{BEHAVIOUR DEVELOPMENT}

This section brings together sparse information on the ontogeny of some of the patterns based on more or less casual observations.

6 day old chicks already showed headshaking, both wing stretching, body shaking and a poorly coordinated preening. On the same day chicks also showed a stretching of both legs and drooping of one wing down and backwards, this presumably being a precursor of the adult wing and leg stretch (DILGER, 1956). It could be observed up to the age of I I days, while the proper wing and leg stretch was first observed in 9 day old chicks. On this day wing flapping was first observed, a movement which consisted of extending and flapping the wings up and down synchronously, and while it is possible that this represented incipient flying, it did seem remarkably similar to the wing flapping shown by adult gulls, in which species the movement is clearly some sort of stretching. On the Igth day of life head scratching was seen for the first time, but it was not possible to decide whether it was performed by the above or below the wing method due to the shortness of the wing. Movements strongly resembling sand bathing was also seen at this age, but it was poorly coordinated and functionally unef fective.

When the chicks leave their nest on the Ioth day of life they move about by hopping, and walking is not well developed till the I5th day, on which date flying appears. Feeding on their own begins on the I7th day and they become independent on about their 28 th day of life.

\section{INHOMOGENEITY AND TRENDS}

Two types of non-stationarity are pertinent in the present context. First, the various data samples may not be equivalent in their statistical properties because they stem from different individuals, sexes, etc., which are nonidentical as systems, i.e. one is dealing with a non-homogenous population of systems. Second, the output of a system in response to a stationary input may change over time, due to development, learning, etc., i.e. the systems statistical properties not being invariant with respect of time or else the outputs of a stationary system are non-stationary because say, due to seasonal changes in the physical environment, the system is subject to non-stationary inputs.

While there are not sufficient data to examine differences between individuals Tab. I shows that there are marked and often significant differences between the sexes in the mean rates of occurrence and their variance in several of the patterns studied, suggesting that the sexes are 
non equivalent systems also with respect to their non sexual behaviour. This is supported by striking sex differences found in a number of interbehaviour correlations (Fig. 7).

Regarding trends, changes in the behaviour are obvious as the season advances and I have examined this more closely, again only in terms of mean frequencies. Fig. 8 and 9 show the relevant information, all comfort patterns having been lumped for this purpose. Although there is a great deal of variation, there is a clear indication of trends, probably different for males and females. While in the females, for both flying and comfort

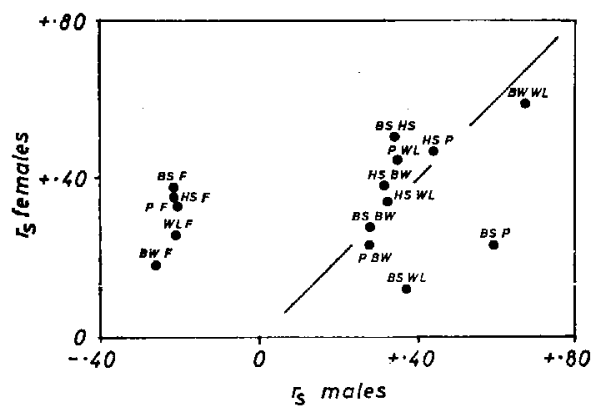

Fig. 7. Comparison of inter-behaviour frequency correlations of males and females. The Spearman coefficients are derived from II8 (males) and 44 (females) $30 \mathrm{~min}$. observation periods on several individuals.

\section{TABLE I}

Comparison of mean frequencies of occurrence and their variance between males and females for various behaviours

Bodyshake

Sratching

Preening

Both wing strech

Wing and leg stretch

Flying

Bodyshake

Scratching

Preening

Both wing stretch

Wing and leg stretch

Flying

\section{Mean}

$\begin{array}{ccc}\text { Male } & \text { Female } & p \\ \text { 1.67 } & 1.09 & <0.05 \\ 0.49 & 0.75 & \text { n.s. } \\ 0.39 & 0.61 & \text { n.s. } \\ 0.24 & 0.81 & <0.005 \\ 0.23 & 0.20 & \text { n.s. } \\ 5.15 & 3.39 & <0.005\end{array}$

Standard deviation

$\begin{array}{ccc}\text { Male } & \text { Female } & p \\ \text { 2.I0 } & \text { I.13 } & <0.005 \\ 0.98 & \text { I.I5 } & \text { n.s. } \\ 0.79 & \text { I.I7 } & <0.005 \\ 0.58 & 0.95 & <0.005 \\ 0.68 & 0.54 & \approx 0.05 \\ 3.76 & 2.20 & <0.005\end{array}$

Based on II 8 (males) and 44 (females), 30 min observation periods on several individuals. Probabilities based on $t$ and F-tests on the suitably transformed data. 
behaviour there is a tendency for increase as the season proceeds, in the males more structured trends appear to be operating, but I can not clearly adscribe them to any particular causal mechanisms.

The occurrence of at least some behaviour patterns is also, not surprisingly, subject to diurnal fluctuation. As Fig. IO shows, these trends appear to be different for different patterns and although only two activities exhibit highly significant trends, i.e. flying and stretching, they happen to be almost symmetrically divergent. The preening frequencies in 2 separate sets of data, stemming from birds under very different con-



Fig. 8. Seasonal trends in the frequency of comfort behaviour and flying of males. Based on approx. 59 hours of observation on essentially a single male. The size of the circles indicate the duration of the observation ranging between 30 mins. and 5 hours.

The trend line is a weighted sliding average over 5 observation periods.

ditions show reasonably concordant and just significant trends, which seem however, to be different again from those mentioned above.

Similar variety in diumal trend patterns also apply for other Skylark behaviours (DeLIUs, 1963), and no simple model seems to account for all these diverse trends. More casual observations also suggest that the daily trends may change in the course of the season, perhaps in response to changes in day length. Under the circumstances there is no way of deciding to what extent these daily fluctuations reflect endogenous circadian thythms as found in birds kept under constant environment conditions (Aschoff, I96I), or represent responses to environmental stimuli varying with the daily cycle; probably they are compound effects of both.

In spite of having found the behaviour patterns affected by trends re- 
flecting non-stationarity, no corrections beyond adjusting the means of some samples were applied before proceeding with the analysis, since it was felt that the trends are relatively slow as compared with the time scales of the processes to be examined, and that such corrections would have been of doubtful value due to the statistical uncertainty of the estimated courses of the trends. Further, some of the later analyses will be done using selected data, not exhibiting at least some of the trends and inhomogeneities discussed.

\section{STIMULUS RESPONSES}

Since in the remainder of this paper I will only analyse the behaviour systern of Skylarks in terms of its output with the consequential difficulty

Fig. 9

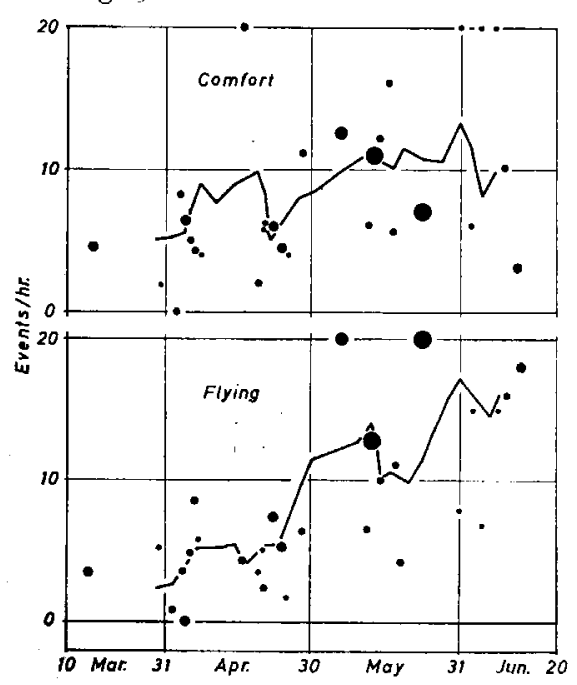

Fig. Io

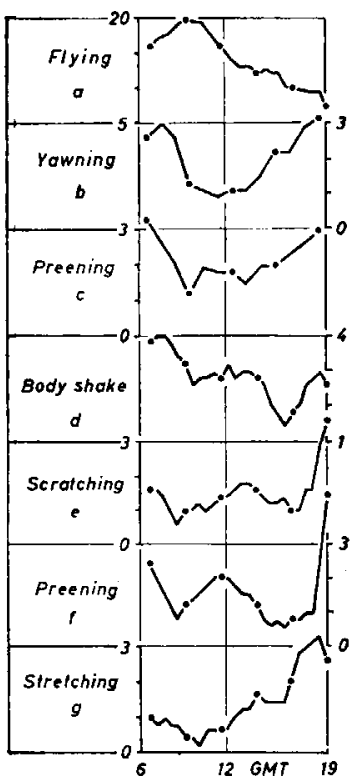

Fig. 9. Seasonal trends in the frequency of comfort behaviour and flying of females. Based on approximately 30 hours of observation on several females. The size of the circles indicate the duration of the observation periods ranging between 30 mins. and 2 hours.

Fig. Io. Daily trends in the frequency of various comfort patterns and flying. $\mathrm{a}, \mathrm{d}, \mathrm{e}, \mathrm{f}$ and $\mathrm{g}$ based on $\mathrm{I} I 0 \mathrm{30}$ mins. observation periods on 3 males between the I7th April and 8th May. Lines are moving averages over $2 \mathrm{l} / 2$ hours. Points represent independent $2 \mathrm{~T} / 2$ hours samples. $\mathrm{b}$ and $\mathrm{c}$ are based on 56 hotirs of observation at the nest of a single female. The lines are moving averages over 3 hours and the points are independent 3 hour samples based on the nest time during that period. For a and $\mathrm{g}$ $\mathrm{p}<0.00 \mathrm{I}$, for $\mathrm{c}$ and $\mathrm{f} \mathrm{p}<0.02$, for remainder non significant. The probabilities are based on the independent samples (Kruskal Wallis test). 
in adscribing the relationships obtained to either the system or the environment, as discussed before, I will briefly examine their behaviour in terms of responses to environmental stimuli.

The only stimulus which could be effectively controlled was the presence of the observer in the territory of the birds. Fig. I I shows the Skylarks response in terms of probability of occurrence time courses for several behaviour patterns. Since obviously no pre-stimulus records could be obtained, the mean probability derived from long observation periods has been

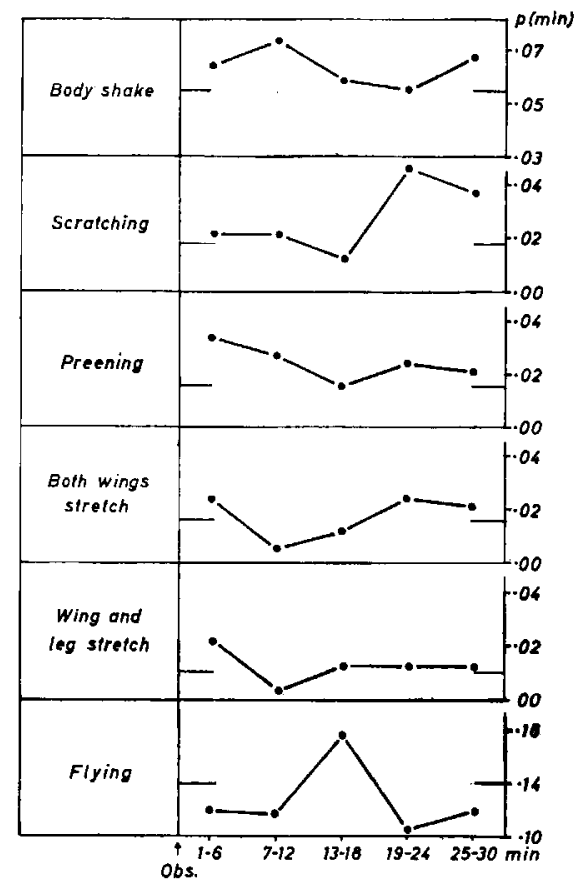

Fig. II. Response to the arrival of the observer. Based on 66 observation periods on scveral males and females, the points giving the mean rates of occurrence for 5 mins. intervals. For scratching the Kruskal Wallis test $\mathrm{p}<0.0 \mathrm{I}$, remainder $\mathrm{p}>0.05$. Horizontal lines give mean rates from long records.

used as baseline instead. This precludes assessing the steady state response to the stimulus. While all patterns evidence some fluctuations which could be responses to the appearance of the observer only that of headshaking is significant. This however has to be viewed cautiously since there are problems of non independence which can not be adequately coped with, and also because we are testing a posthoc hypothesis. If the results are valid, then they suggest that Skylarks respond to the arrival of the observer with an appreciable increase of scratching with a latency of some is mins. 
While it is not possible to interpret this result neither causally nor functionally at present, I suggest that this is a response similar to that found experimentally in rodents, which when exposed to novel stimuli will also show delayed changes in behaviour, often in form of increased grooming (e.g., Bindra \& Spinner, 1958).

Less definite data is available for responses to weather changes although from casual observations it was quite clear that such did exist. It proved however impossible to establish any clearcut relationships with the maintenance behaviour shown by the Skylarks, this failure probably being due to both the coarseness of the weather records and the complexity of weather in terms of the physical variables recorded, such as temperature, wind, sunshine, etc. The Skylarks namely seemed to be responding to the weather in terms of "good" or "bad" rather than to the single variables and these characterizations depend in a complicated way on the individual variables.

The following notes are based on impressions obtained in the course of the study. Bodyshake was facilitated by fine slow rain and inhibited by cold, wind and heavy rain. Preening was similarly inhibited by these but probably activated by warm temperatures. Sand bathing and sun bathing were certainly highly dependent on higher temperatures, or perhaps more correctly on high heat absorption. Both were inhibited by rain, sand bathing in a persistent way since wet soil effectively prevented it. Rain bothing conversely was totally dependent on fine slow rain. For most of these patterns the transient effect of weather changes were more apparent than the steady state changes.

Another source of stimuli which seemed important in controlling maintenance activity was the behaviour of sexual partners, offsprings and neighbours, but the interactions were so complex that no clearcut conclusions could be reached about the relationships. To be able to do so would require simultaneous records of the behaviour of the social partners, a task which was not possible under field conditions. What seemed to complicate the issue were the mutual effects the behaviour of the partners have on each other, i.e. the causal loops within the social groups.

Illustrating a simpler case of a causal loop one might mention the frequent occurrence of head shaking as response to objects the Skylarks pecked up, where the stimulus was a direct consequence of their own behaviour.

\section{SEQUENTIAL ORGANISATION}

An often used way of describing the organisation of behaviour is through 
matrices of transition probabilities between behaviour patterns, indicating how often given patterns are either followed or preceded by other specific patterns. Such a description is given here for comfort behaviour 1 ), but because it appears that comfort patterns tend to be shown in bouts (see later), i.e. in strings not interrupted by other behaviours, the analysis was done separately for such comfort behaviour bouts and for comfort patterns not occurring in bouts, i.e. separated by longer intervals and other types of behaviour.

Fig. I2 presents the information for the comfort behaviour of Skylarks

\begin{tabular}{|c|c|c|c|c|c|c|c|c|c|}
\hline Following & 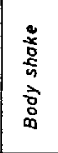 & 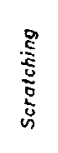 & & 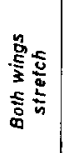 & 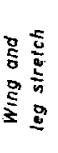 & 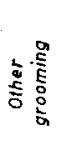 & $\frac{\sqrt{5}}{5}$ & 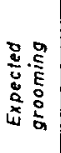 & 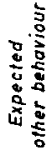 \\
\hline Body shake & .000 & .190 & .290 & $\cdot 173$ & .008 & .304 & $\cdot 324$ & $\cdot 191$ & $\cdot 256$ \\
\hline Scrotehing & .095 & $\cdot 155$ & .245 & .048 & .029 & . 130 & 1.180 & $\cdot 132$ & .176 \\
\hline Preening & .143 & .259 & .000 & .000 & .000 & .043 & 1.144 & $\cdot 102$ & -137 \\
\hline $\begin{array}{l}\text { Both wings } \\
\text { stretch }\end{array}$ & .298 & .034 & .044 & .032 & .618 & .023 & -081 & $\cdot 741$ & $\cdot 180$ \\
\hline $\begin{array}{l}\text { Wing and } \\
\text { leg strefch }\end{array}$ & .059 & .017 & .044 & .178 & .059 & .000 & -117 & .077 & .103 \\
\hline $\begin{array}{l}\text { Other } \\
\text { grooming }\end{array}$ & $\cdot 119$ & $\cdot 103$ & .044 & .065 & .000 & $\cdot 152$ & $\cdot 154$ & $\cdot 105$ & .160 \\
\hline $\begin{array}{c}\text { Other } \\
\text { behoviour }\end{array}$ & .286 & .242 & .333 & .564 & .206 & .348 & - & $\cdot 252$ & - \\
\hline Notol & 1.000 & 1.000 & 1.000 & 11.000 & 1.000 & 1.000 & 1.000 & 1.000 & 1.000 \\
\hline$N$ & 84 & 58 & 45 & 62 & 34 & 46 & 111 & 440 & 329 \\
\hline
\end{tabular}

Fig. I2. Transition probabilities between comfort patterns when the interevent intervals are less than one minute. Based on $8 \mathrm{I}$ hours of observation on several males and females. Framed transitions depart significantly $(\mathrm{p}<0.05$, chi square) from null order model.

when the patterns occurred in bouts. It will be noticed that it also includes theoretically expected probabilities derived from assuming that given the frequencies with which they occur, the behaviour patterns follow each other randomly. Some marked and significant deviations from these expected probabilities do occur, suggesting that there is a probabilistic structure in the comfort bouts.

Little can be said about the causal background of such departures from randomness, some may be simple consequences of coordination mechanisms

I) For purely technical reasons flying is omitted from this section. 
in the nervous system and I think that the high probabilities with which wing and leg stretch is followed by both wing stretch and conversely, may be perhaps an example of this. Others may reflect correlations of the environmental stimuli which cause independently - as far as the animal's system is concerned - the concatenated patterns, this perhaps being the case when preening tends to be followed by scratching, and inversely, if one assumes that both are due to itching agents which are obviously likely to affect simultaneously and indiscriminately both he head and the trunk of the bird. Apart from positive relationships a number of negative ones are apparent, such as for example the tendency of body shaking not to be followed by body shaking again, suggesting that some sort of inhibition follows the performance of this behaviour. Again it is possible that some transitions in this category go back to negative correlations in the environmental causes. Regarding the initiation and end of bouts there is a clear tendency for both wing stretch to terminate a sequence and not to initiate it.

An independent although less complete set of observations supports the organisation of comfort behaviour bouts suggested by Fig. 12 except that it also indicates a rather marked tendency of preening being followed by body shaking, this perhaps being an example of one activity engendering the stimulus, here dishevelled plumage, which causes another.

Higher order transition probability structures may have to be explored, if the transitions obtained are not capable of predicting, say, the probability of body shaking occurring after the doublet grooming, scratching has occurred. The limited data did not allow meaningful further analysis along these lines, but other workers have made extensive use of this type of description (Nelson, i964; Altmann, i965).

Another question is if the same structure persists when the component patterns do not occur in bouts, that is when the intervals between the patterns are of one minute or longer duration and are interspersed with non grooming behaviour patterns. Fig. I3 shows the relevant probability matrix. Not surprisingly in this instance only 3 transitions differ significantly from the expected random model 1 ), indicating that time or the intercalated behaviour disrupts the organisation just mentioned. Additionally the 3 significant deviating transitions do not agree with the corresponding ones obtained for the bouts, they seem to be just the reverse. For body shaking, for example, it appears, that after the brief period of inhibition mentioned above there is one of facilitation following.

I) If the total number of transitions is inflated to be equivalent to the total analysed in the bout situation then 5 transitions are significant. 


\section{ORGANISATION OF PREENING}

As mentioned before, preening, which has so far been treated as a point event, consists in fact of strings of a number of more or less well defined movements, briefly mentioned in the descriptive chapter. There can be no doubt that these movements have a marked linkage among themselves, which make them occur in bouts and only very rarely as isolated single movements. It is in fact possible that the occurrence of such isolated preening movements may be due to factors different from those causing preening bouts as suggested by the disproportionate frequency of two movements: preening

\begin{tabular}{|c|c|c|c|c|c|c|c|}
\hline Following & 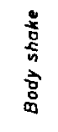 & 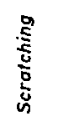 & 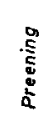 & $\begin{array}{l}\frac{y}{5} \\
\frac{5}{5} \\
5 \\
\frac{5}{0} \\
0 \\
0\end{array}$ & 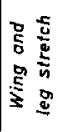 & 웜 & 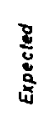 \\
\hline Body shake & .673 & -461 & $\cdot 342$ & -344 & $\cdot 231$ & $\cdot 385$ & .497 \\
\hline Scratching & .095 & .282 & $\cdot 158$ & $\cdot 186$ & .231 & $\cdot 115$ & .140 \\
\hline Preening & $\cdot n$ & .077 & .184 & $\cdot 156$ & .077 & .077 & $\cdot 108$ \\
\hline $\begin{array}{c}\text { Both wings } \\
\text { stretch }\end{array}$ & .042 & .026 & .079 & $\cdot 125$ & .077 & .038 & .043 \\
\hline $\begin{array}{l}\text { Wing ond } \\
\text { leg sireleh }\end{array}$ & .024 & .077 & .079 & .031 & .153 & .019 & .049 \\
\hline $\begin{array}{c}\text { Other } \\
\text { grooming }\end{array}$ & $\cdot 125$ & .077 & .158 & $\cdot 156$ & .231 & .366 & .163 \\
\hline Total & 1.000 & 1.000 & 1.000 & 1.000 & 1.000 & 1.000 & 1.000 \\
\hline$N$ & 160 & 39 & 38 & 32 & 13 & 52 & 344 \\
\hline
\end{tabular}

Fig. 13. Transition probabilitics between comfort patterns for interevent intervals of more than one min. Based on the same data as Fig. I I. Framed transitions depart significantly $(\mathrm{p}<0.05$, chi square $)$ from null order model.

of belly and of tail covers. These instances however, did not seem to be particularly connected with occurrences of displacement grooming as could be expected on the basis of VAN IERSEL \& BoL's (1958) studies of terns.

The duration of preening bouts in terms of movements varied widely, a strong deficit of bouts consisting of few movements and an excess of such involving ten to fifteen movements, compared against an expected random distribution. This suggests that preening has a self-activating effect up to about fifteen movements. The movements proceeded so fast that it was not possible to record them more than partially. A transition probability matrix was derived from these incomplete notes and it suggests that the following 
transitions were relatively more frequent than others: neck to breast, breast to belly, belly to wing bow, belly to wing underside, wing underside to back, back to wing bow and back to wing inside. Switching from one side of the body to the other to perform the same preening movements appeared to be rare, the impression being that the animals proceeded with several movements along one side before they changed over to the other side, as seems to be the case in the preening of gulls (R. G. B. BRown, pers. com.).

\section{INTERVAL ORGANISATION}

Another way of describing relationships between behaviour variables which has been used in the past is that of giving interval distributions (Eisner, I963; Delius, I963; Nelson, i964; Schleidt, I965). This information on the times between behavioural events is helpful in indicating deviations from random occurrence although it will not necessarily do so since the departure from randomness may not be in the distribution of intervals but in their sequential organisation.

For reasons of convenience I have chosen to plot the distributions semilogarithmically and cumulated backwards, the first procedure giving a straight line when the events are generated by, among other, a Poisson process, the slope thereof indicating the rate of occurrence which is not essentially modified by the second procedure that avoids the inconvenience of zero frequencies (NELSON, 1964). While the interval distributions for a single behaviour pattern entail no ambiguities in the case of joint interval distributions, I have perhaps arbitrarily, selected intervals bounded by the relevant patterns in the order specified and not interrupted by the occurrence of either ${ }^{1}$ ). If the behaviour patterns occur randomly, then the rate of this joint distribution is equal to the product of the rates of the parent processes (Cox, in lit.).

My data present certain difficulties. Some of the behaviour patterns occurred at very low rates, i.e. with long mean intervals as compared with the observation periods. This leads to a preferential sampling of the shorter intervals from the true distribution, as could be seen when comparing the mean intervals for the different behaviour patterns derived from dividing the total observation-time by the number of events against the mean intervals derived from the interval distributions, where the latter were consistently shorter. The effect this has on the distributions plotted semilogarithmically is

I) If this specification is restricted further so as not to allow interval interruption by any of the other events then the interval distribution matrix is a generalization for all interval spans of the transition probability matrices for $\mathrm{o}$ and $>\mathrm{I}$ min intervals given above. 
to increasingly deflect the plot downwards the longer the intervals and more markedly so the smaller the rate of the underlying process, suggesting a higher rate of occurrence than the true one due to the resulting steeper slope. Kolmogorow Smirnov tests done on the original non cumulated data against expected exponential distributions are affected by this and give rise to misleading probabilities. Therefore they are not given here.

Examining Fig. I4 with this in mind suggests that a number of distributions may conform with Poisson processes, such as for example those of flying, bodyshaking-preening; scratching-wing and leg stretch. Very many

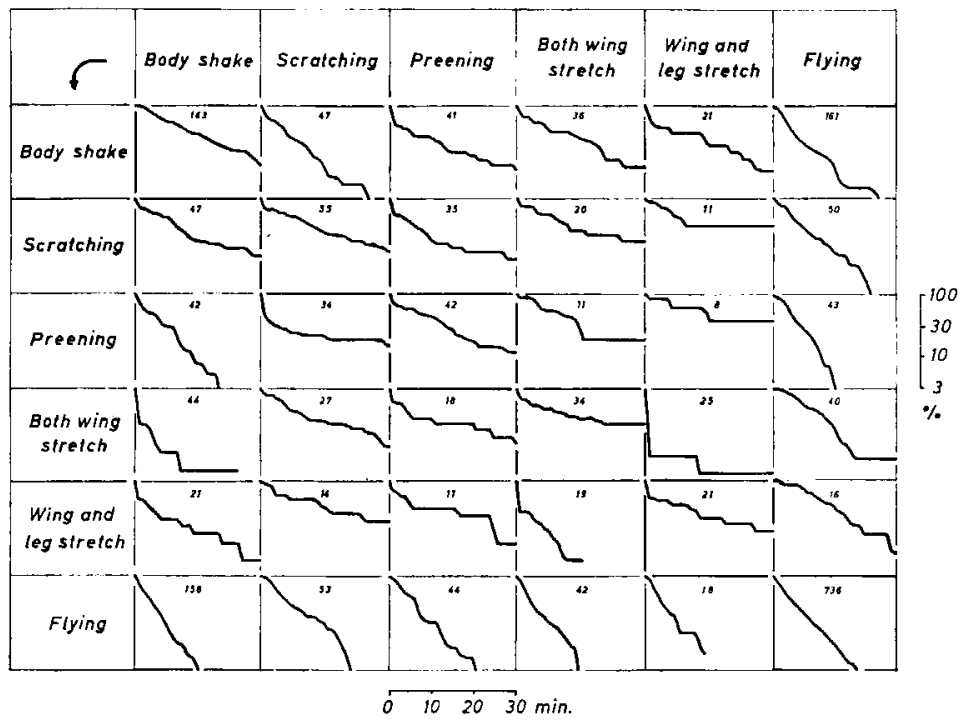

Fig. 14. Interval distributions cumulated backwards and plotted semilogarithmically in percentages of the total indicated by the figures. See text for specification of joint intervals. Top row patterns precede right column ones. Based on 8I hours of observations, several males and females.

however clearly deviate from such model by showing an excess of zero and short intervals, this being so in the histograms for example, for scratching, scratching-preening, bodyshake-both wing stretch, implying that in these cases there is a tendency for the pattern to occur in bouts. In a few other histograms, such as those of bodyshake, scratching-flying, flying-both wing stretch, etc., the reverse tendency appears to be operating, i.e. there are too few short intervals for them to agree with random occurrence.

Striking differences, particularly regarding slopes, can be noticed between the corresponding converse joint distributions which should be equivalent on the assumption of random relations between the two series of events. The 
asymmetries suggest that there are persistent tendencies for given behaviours to follow certain and not other patterns. Examples for this are the histogram pairs scratching-body shake and body shake-scratching, preening-body shake and body shake-preening, as well as many others. Generally it can be concluded that the grooming patterns tend to have distributions with an excess of zero and short intervals, while those involving flying either show the reverse trend or seem to be exponential distributions. From this it follows
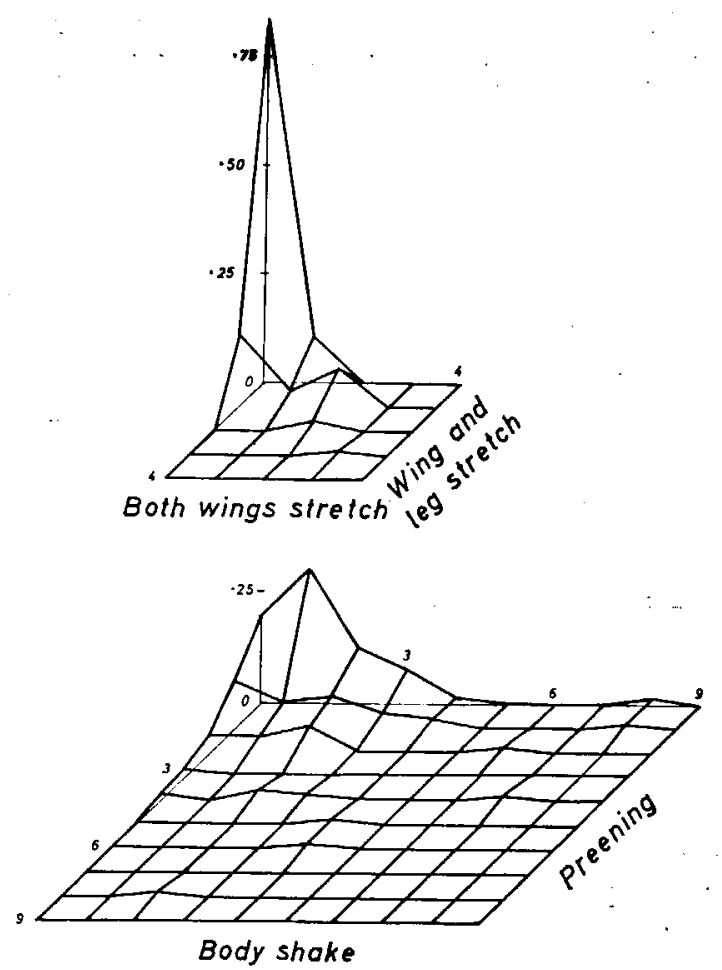

Fig. I5. Joint count distributions. Body shake-precning and wing and leg stretch - both wings stretch histograms as samples. Notice that the histograms are threedimensional. Based on I Io $30 \mathrm{~min}$. observation periods on three males between I7th April and 8th May.

that the comfort patterns tend to occur in bouts, or at least associated in time, while flying is to a large extent excluded from this association.

Additionally to these interval distributions, count or frequently distributions exist which are virtually equivalent in information content. However, regarding joint distributions a more general version than that used here can be given. Their disadvantage is that they are somewhat difficult to interpret as the samples given in Fig. I5 show. 


\section{FREQUENCY CORRELATIONS}

Apart from the types of quantitative descriptions so far treated many authors also give matrices of correlation coefficients between the behavioural variables where these are quantified in terms of frequency of occurrence in some arbitrary time units. It has been suggested at least by two workers (J. M. Cullen, pers. com.; W. M. Schleidt, in Heiligenberg, I963) that this latter, the time unit, might be important. Therefore the correlations are presented here as functions of the arbitrary time units (Fig. I6).



Fig. 16. Frequency correlations as functions of the unit observation periods. For the I5 min. unit the correlations are based on 18 hours observation on one male, the data being part of the 55 hours of observation on three males between 17 th April and 8th May used for the 30, 60 and 120 mins. unit correlations. The correlations marked s are based on 59 hours of observation on essentially a single male over the whole breeding season, divided in mean periods of 90 mins. (30 mins. -300 mins.). The coefficients are Spearmans $r_{s}$, and $p=0.95$ confidence intervals are indicated. Note that for the row "flying" the base line is - 0.40 whereas for the others it is zero. For all rows the ordinate spans over 0.60 coefficient units.

It is obvious that the correlations are as a rule functions of the sampling unit and that these functions can take quite different forms from case to case, monotonously increasing as in the case of bodyshake-preening, decreasing like in scratching-flying, or non-monotonous as in scratching-wing and leg stretch. Even more, for given behaviour patterns pair correlations may be zero for one unit while positive for another, i.e. scratching-both wing stretch, or positive correlations may turn negative at another sampling unit duration, i.e. scratching-flying.

This indicates that the correlation matrices based on a given time unit are 
of restricted value in typifying the relationship between behavioural variables. On the other hand the presentation used here is somewhat difficult to interpret. The reader will see that crosscorrelation functions both explain the phenomenon just described and also provides an accurate way of summarizing the underlying processes.

\section{CORRELATIONS WITH OTHER BEHAVIOUR}

Table 2 presents the correlation coefficients for half hour frequences between the five comfort patterns and flying, sexual behaviour, that is courtship, aggressive behaviour, i.e. fighting and threatening, and aerial singing. Most coefficients are very low and only a few are significant, these being associated with stretching movements. It is also worth noticing that I 5 out of 20 coefficients are negative (Binomial, $p<0.05$ ), suggesting that the comfort movements belong to a class of their own. This is supported by the fact that all ro intercorrelations between the comfort movements

\section{TABLE 2}

Frequency correlation coefficients (Spearman's $r_{s}$ ) between comfort, flying and reproductive behaviour

$\begin{array}{lcccc} & \text { Sex } & \text { Aggression } & \text { Singing } & \text { Flying } \\ \text { Bodyshake } & +0.06 & -0.01 & -0.00 & +0.05 \\ \text { Scratching } & -0.06 & -0.14 & +0.04 & -0.15 \\ \text { Preening } & +0.14 & +0.10 & -0.1 \mathrm{I} & -0.12 \\ \text { Both wing stretch } & -0.01 & -0.14 & -0.22^{*} & -0.16^{*} \\ \text { Wing and leg stretch } & -0.10 & -0.16^{*} & -0.22^{*} & -0.26^{*}\end{array}$

Based on I 1030 min. observation periods on 3 males between April 17th and May 8th. The coefficients marked with asterises are significant at $p<0.05$.

are positive, 3 of them significantly so $(\mathrm{p}<0.05)$, again for 30 mins. On the basis of some studies on other birds and mammals there is reason to believe that they are facilitated by an incipient activation of sleep mechanisms (Delius, 1967). The present data do not contradict this hypothesis since all 4 non-comfort patterns can be associated with marked wakefulness, i.e. general arousal, 4 out of the 5 correlations coefficients interrelating them being positive, 3 of them significantly so $(p<0.005)$. Further, data obtained from incubating females yields a high positive correlation (Fig. I $7, \mathrm{r}_{\mathrm{s}}=$ $+0.6 \mathrm{I}, \mathrm{p}<0.00 \mathrm{r})$ between yawning and preening frequencies, yawning being clearly associated with dozing, which unfortunately could not be quantified.

A more balanced judgement on this issue must be reserved till fuller 
descriptions of the relationships perhaps in the form of crosscorrelation functions are available, since as we have seen correlation coefficients as used here give a very partial picture. From castual observations there appears to be a tendency for sexual behaviour to be associated with preening in the male and with preening and sand bathing in the female, and this may be reflected in Table 2 by giving the only appreciable positive coefficent. Further, on rare occasions striking occurrences of preening were recorded embedded in very

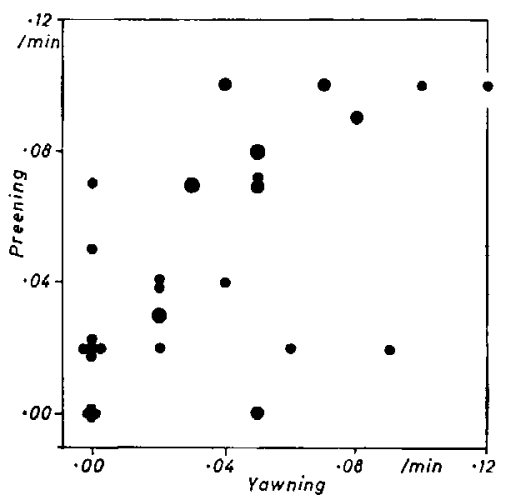

Fig. 17. Correlogram for prcening and yawning. Based on 28 hours of observation on a single incubating female. The size of the circles indicate the time on the nest in each hour on which the preening and yawning frequencies were calculated (ranging between 40 and 60 mins.).

active agonistic encounters, perhaps representing displacement activities, but as mentioned groundplucking was far more common in such situations (Delius, 1963).

\section{AUTO- AND CROSSCORRELATIONS}

As next step in the analysis the auto- and crosscorrelations of the count processes were obtained. Although generally it is desirable to keep the time unit of the count process as small as possible so as to ensure a suitable time resolution of the correlation functions and correspondingly a reasonable frequency resolution in their transformation, the power spectra, here I have been forced to use a $30 \mathrm{~min}$. unit because most of the data suitable for this analysis are irretrievably cast in such form. This is unfortunate since it is probable that the more interesting features of these functions lie in fact within this time period.

Nevertheless Fig. I 8 which gives the matrix of auto- and crosscorrelation based on the 30 mins. frequencies of behaviour patterns, reveals the importance of this type of analysis. The reader will remember that the 
autocorrelation functions are symmetrical for negative and positive lags and that further for zero lag they obviously assume the correlation value of plus one. The crosscorrelations on the other side are typically nonsymmetrical and do not anywhere assume any value specified a priori. If it is desired to obtain the converse, complementary functions from the cross correlation functions given, i.e. to transform the function scratching-preening into the preening-scratching one, then all that needs to be done is to change the sign of the lags, i.e. positive lags become negative and negative ones positive.

Examining first the autocorrelations, we find that for example that of scratching decays to zero correlation with the largest lag in a fairly continuous manner as it is typical for wide frequency band random noise,

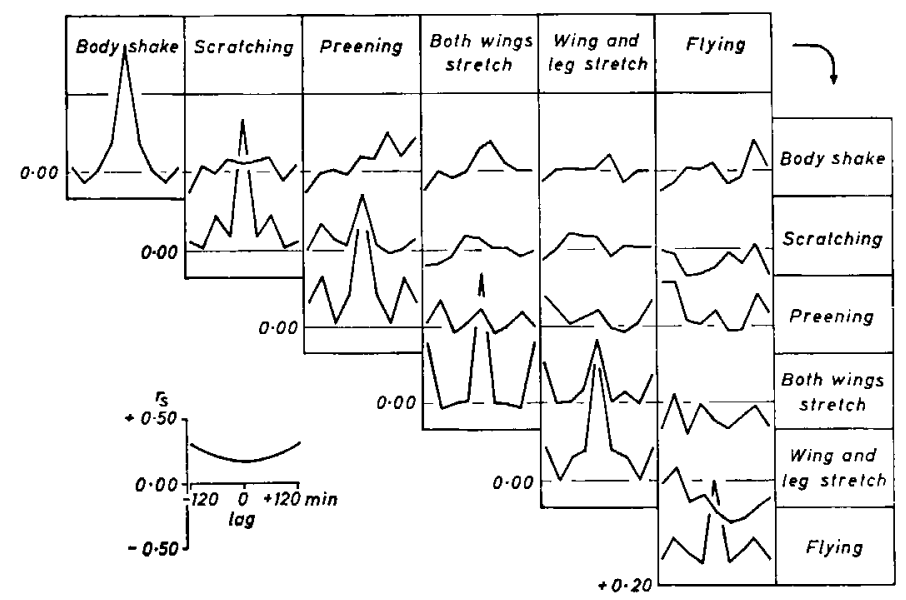

Fig. I8. Auto and crosscorrelation functions, based on I Io 30 min. observation periods on three males between I7th April and 8th May. The inset indicates the critical correlation coefficients for $p=0.05$. Based on Spearman coefficients.

while that, for example, of preening and both wing stretch shows secondary peaks at larger lags suggesting loose rhythmicities as in narrow band noise, i.e. if for example the frequency of both wing stretch has been above average in a given half hour it is likely to be similarly high in the half hour period two hours later, and to have been high two hours before. The lags corresponding to these secondary peaks however are not always the same in the different functions suggesting that the rhythmicities are of different median frequencies for the different patterns.

The crosscorrelations show a variety of patterns. Firstly a few are approximately symmetrical, i.e. wing and leg stretch-both wing stretch, indicating that the temporal relationships between the two patterns are nearly equivalent i.e. if both wing stretch has occurred at an above average 
frequency in a given half hour, then wing and leg stretch is likely to occur at high frequency 2 hours later and conversely if wing and leg stretch occurs frequently in a given half hour then both wing stretch will also be more frequent than average 2 hours later. Others do not show any symmetry like for example the function preening-scratching, where, while there is no significant correlation at zero lag, there is one at one hour lag, i.e. high frequency of scratching is likely to follow above average frequency of preening an hour later, the converse not being true. Marked negative correlations do also occur in the crosscorrelation functions, i.e. in the case of flying-wing and leg stretch. Here given that flying was frequent in a given half hour, it is particularly unlikely that wing and leg stretch will be also more frequent than average half an hour later.

The picture Fig. 18 presents is however, as indicated above, only a coarse one. Auto- and crosscorrelations, based on 15 mins. units, but unfortunately with considerably less data, suggest that much detail of the temporal relationships between the behaviour patterns is lost. For example, it is virtually certain that in the autocorrelation function of both wing stretch the use of 30 mins units has suppressed a marked positive correlation at 60 mins lag because it happens that at 45 and 75 mins lag the function takes negative values. The point is further reinforced by the following section, which indicates that a resolution of less than 15 mins is desirable, as then for example, there is an indication that the both wing stretch autocorrelation should have a further positive peak at about 20 mins lag, which is missed even by the 15 mins unit analysis.

Generally, temporal relationships between the occurrences of behaviour patterns show capricious particularities of their own and quantitative descriptions not including them must be necessarily incomplete.

\section{INTENSITY FUNCTIONS}

Although these functions are essentially equivalent to auto- and crosscorrelations (ZADEH, I957) they are given here because of the ease with which they can be interpreted as they indicate the time course of the mean rate of occurrence of a given behaviour pattern after the same - or as the case may be - other pattern has occurred. Also they enable us to present correlation functions with a finer time resolution than in the previous section due to the fact that more data is available for this type of analysis. It has the disadvantage however of being somewhat unhomogeneous. Intensity functions have been used before in behaviour descriptions, i.e. by Delius (1963) or more explicitly by SchleIDT (1965) and they are almost routine among 
neurophysiologists, usually however under different names (MOORE, Perkel \& Segundo, rg66). Fig. I9 indicates how these functions are obtained from the data.

Examination of the matrix of intensity functions (Fig. 20) reveals a variety of patterns deviating from the expected random horizontal functions. Prominent is the high probability with which most of the comfort movements follow each other and themselves at short time lags, as for example in the case of the preening-bodyshake, the preening-preening and the wing and leg stretch-both wing stretch plots. Notable exceptions where the reverse is true are the both wing stretch-preening, the wing and leg stretch-preening, and bodyshake-bodyshake functions. Virtually all the plots involving flying also

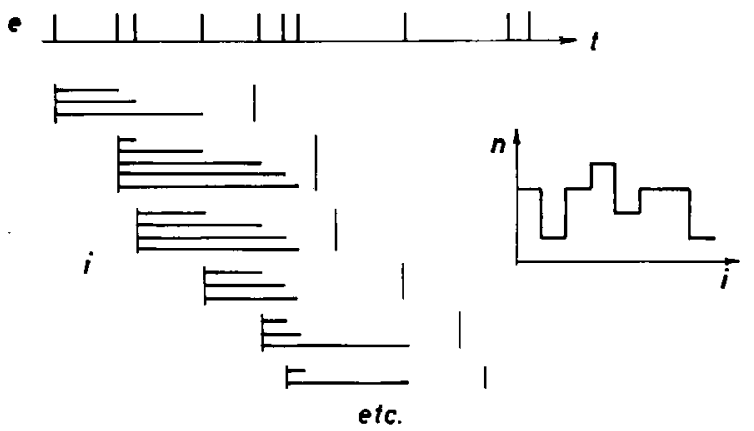

Fig. 19. Obtaining intensity functions from a series of events. The frequency of the intervals $i$ up to an arbitrary and convenient limit, are plotted as fuctions of the durations of $\mathbf{i}$.

showed this latter trend, this relating the findings of the interval analysis in a somewhat more general form. But beyond this some other features emerge which are not, or not easily, assessable in the interval distribution. Such as for example the rebound low probabilities following the short lag peaks just mentioned, as in the both wing stretch-bodyshake, or the wing and leg stretch-bodyshake plots. These depressed probabilities seem sometimes to be followed by delayed peaks as in the case of the preening-preening, the both wing stretch-bodyshake, or the wing and leg stretch-both wing stretch functions. Such peaks at larger lags however are also present in plots, which do not show the pattern just described, as in the both wing stretch-preening, the wing and leg stretch-preening and preening-flying functions for example. Time persistent trends are noticeable in a few functions such as the bodyshake-bodyshake, the scratching-bodyshake and the wing and leg stretchflying plots.

The variety found then is similar as that encountered in the previous 
section and some of the points discussed there do apply in a similar way to the present analysis but it may be worth to point out the similarities found in the intensity functions between the comfort patterns as opposed to those involving flying, suggesting then that in some way these patterns share some causal mechanisms, although the detailed relationships among themselves give evidence of a fair level of complexity of these.

It remains to comment on the statistical significance of these function estimates. Suitable tests are difficult to establish formally and perhaps the simplest would be to obtain confidence intervals using Monte Carlo techni-

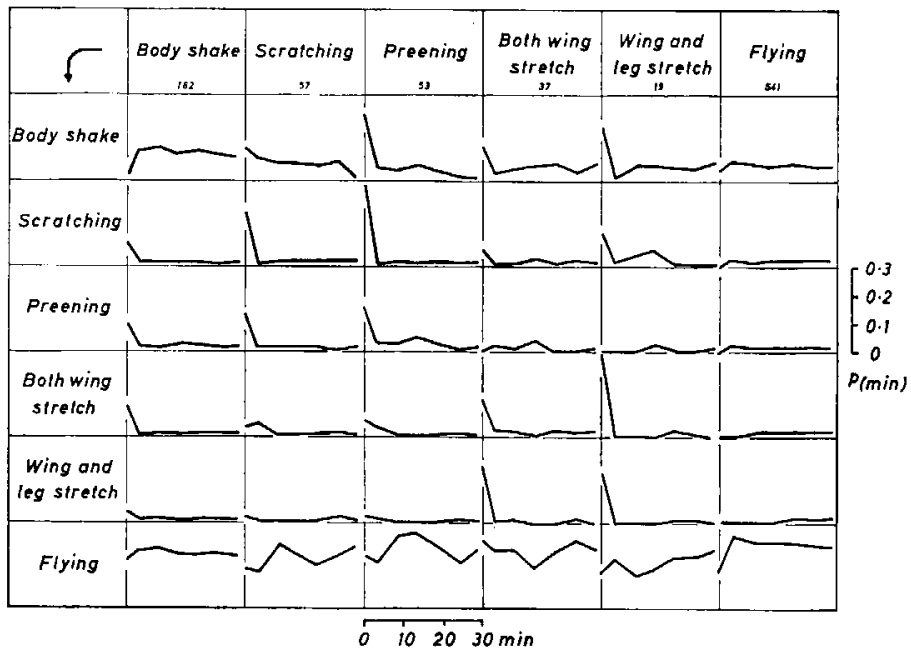

Fig. 20. Intensity functions based on $8 \mathrm{I}$ hours of observation on several males and females. The patterns in the top row indicate the events initiating the intervals. Except for Ist minute the rates are based on $5 \mathrm{~min}$. intervals. The figures indicate the number of events of origin used for each pattern.

ques but this has not been done here and so the results can only be considered as suggestive. As a guide it may be indicated that the goodness of the estimates depends basically on the frequency with which the two events involved do occur, and this can be derived from Fig. 20.

\section{INTERVAL AUTOCORRELATIONS}

As indicated previously a series of events in time can be viewed both as a process of counts and a process of interval where the time base is not true time but the sequence of intervals. Fig. 2 I presents the autocorrelation functions of this latter type of process for bodyshaking, flying and additionally, the combined comfort patterns where these were lumped as equivalent 
events, since there were not sufficient data to obtain functions for the separate individual movements. As noted previously there is no general procedure available for obtaining crosscorrelations of interval processes.

The autocorrelation functions can be seen as supplementing the interval distributions in describing deviations from randomness of occurrence, now regarding the temporal sequencing of the intervals drawn from the distribution.

For bodyshake there is a persistent positive correlation up to a lag of 5 intervals indicating that intervals of similar length tend to occur in runs of on average 5 intervals. For the combined comfort patterns such a

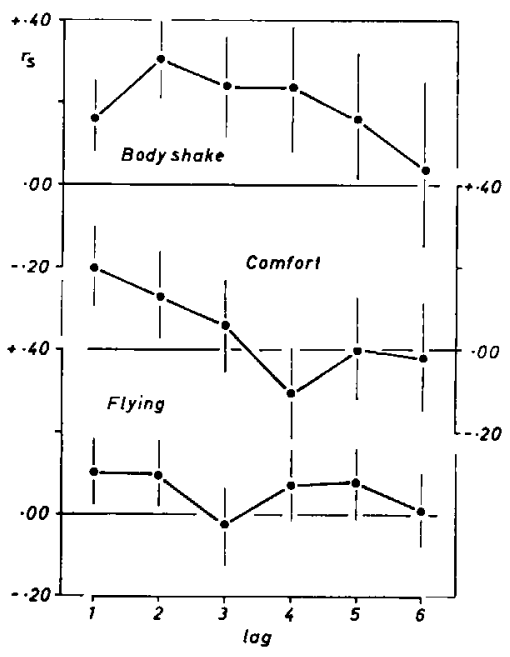

Fig. 2r. Interval process autocorrelations, based on $8 \mathrm{r}$ hours of observation on several males and females. Confidence intervals for $p=0.95$ are indicated. Based on Spearman coefficients.

correlation only lasts over two intervals with an indication of a reversal to a negative one at the 4 interval lag this suggesting that apart from runs of similar intervals there is a definite switch to dissimilar intervals. For flying there is only evidence for not very consistent runs over on average 2 intervals since the correlation coefficients are low.

\section{SPECTRAL FUNCTIONS}

As indicated earlier the correlation function can be transformed mathematically into spectral functions, where the characteristics of random variables and their relationships are given as functions of frequency rather than time. This type of presentation while imparting the same information 
as the correlation function facilitates the assessing of certain features of these characteristics. It is also a prerequisite for deriving the frequency response function relating the variables. Fig. 22 is intended to introduce the reader to the interpretation of these functions.

The spectral functions shown in Fig. 23 are a transformation of the auto- and crosscorrelation functions of comfort behaviour and flying where comfort stands for bodyshaking, scratching, preening and stretching lumped



Fig. 22. Four single frequency signals. They can be thoight as a given frequency component extracted from 4 different random signals. At the frequency given the autospectral density of $A$ is greater than that of $B$ or $C$ (larger average amplitude). The crossspectral density between $\mathrm{A}$ and $\mathrm{B}$ at that frequency is equal to that between $A$ and $C$ but larger than that between $A$ and $D$ (amount of shared 'activity'). The phase relationship equals zero degrees between $\mathrm{A}$ and $\mathrm{B}$, and $\mathrm{A}$ and $\mathrm{D}$, but 180 degrees between $\mathrm{A}$ and $\mathrm{C}$. The frequency response function gain from $\mathrm{A}$ to $\mathrm{B}$ and $\mathrm{A}$ to $\mathrm{C}$ cquals 0.5 and that from $\mathrm{C}$ to $\mathrm{B}$ equals $\mathrm{I}$. The gain from $\mathrm{B}$ to $\mathrm{A}$ is 2 . The coherence equals $\mathrm{I}$ between $\mathrm{A}$ and $\mathrm{B}$ and $\mathrm{A}$ and $\mathrm{C}$ but is close to zero between $\mathrm{A}$ and $\mathrm{D}$, always for the particular frequency.

as a single class of event. There was not sufficient data to warrant a separate analysis of the constituents.

The autospectrum of flying is similar to that of white noise, i.e. the spectral composition of the process covers the complete range of frequencies. The slight fluctuations shown are not likely to be significant except for the relative lack of frequencies below 7 cycles per hour. In the autospectrum 
of comfort behaviour the low frequency components are overrepresented, but peaks at various other frequencies are also prominent. Whether there is any significance in the fact that these peaks occur in two series with equispaced maxima $(6,13,20,27$ cycles and $3,10,17$ and 24 cycles per hour) remains to be examined but at any rate the presence of these peaks

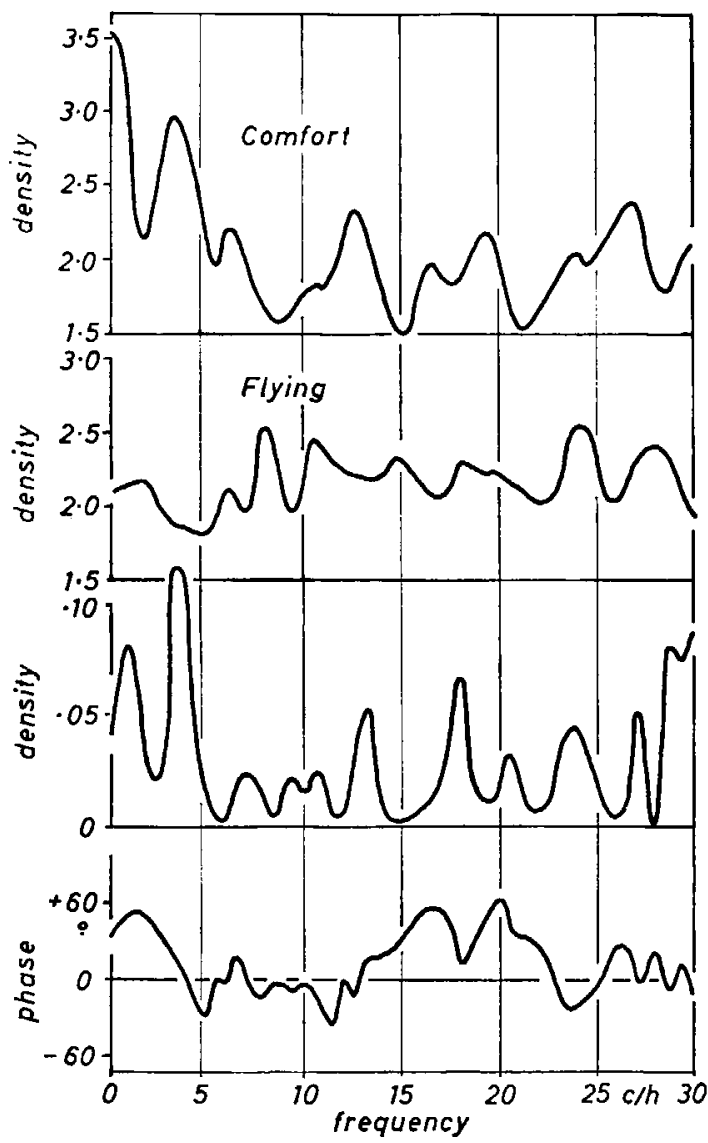

Fig. 23. Spectral and cospectral density functions for comfort behaviour and flying. Transformation of the corresponding count process correlation functions based on 40 hours of minute-to-minute observations of a single male in periods of no less than 2 hours. Note that the cross spectrum consists of a density and a phase function.

suggest that rhythmical processes play an important role in determining the appearance of this behaviour, supporting some earlier findings in this paper. The nature of these rhythmic phenomena is unknown but it seems somewhat unlikely that they could have been due to rhythmical external 
stimulation controlling the comfort behaviour. I rather assume that this reflects some rhythmically active mechanisms in the central nervous system, perhaps such as those found by Scheibel \& Scheibel (I966).

The magnitude of the cospectral density between flying and comfort behaviour is markedly smaller than that of the autospectra indicating that the sharing of activity between the two types of behaviour is restricted. The smaller fluctuations are probably not significant except perhaps for the peaks at I, 3 and 3 cycles per hour. The significance of these peaks would be easier to assess if the phase component of the cospectrum was reliably known, but because of the small densities the phase angles are uncertain.

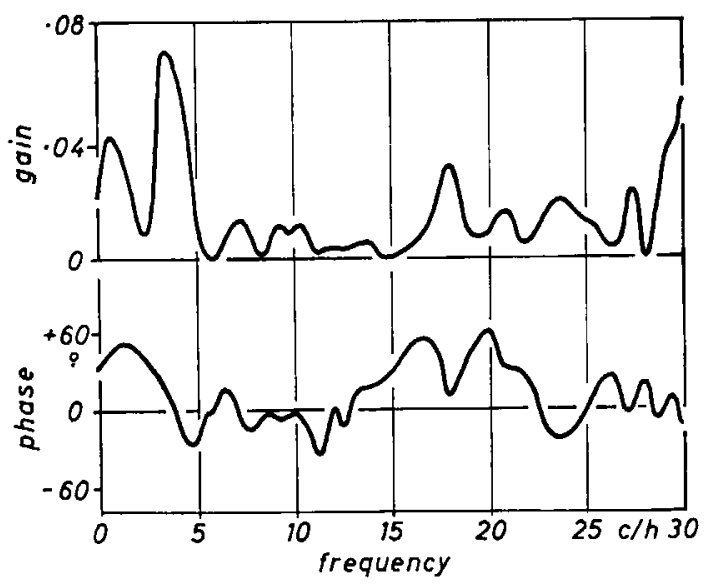

Fig. 24. The transfer function relating comfort behaviour and flying derived from the spectral functions shown in Fig. 23.

It only suggests that at low frequencies up to 5 cycles between 15 and 25 cycles out of phase relationships predominate while between 5 and 15 and above 25 cycles per hour in-phase relationships are preponderant.

From the above functions it is possible to derive the frequency response function and the coherence function relating comfort behaviour and flying. These functions can be considered analogous respectively to the common regression and correlation coefficient. Fig. 24 presents the frequency response function which consists of two components, the gain function and the phase function, the latter being identical to the phase function of the cross spectrum. The gain is low throughout and only a peak at 3 cycles and another one at 30 cycles per hour seems likely to be meaningful. The peak at 3 cycles is possibly associated with out-of-phase activity while that at 30 may in fact reflect in-phase activity. This is roughly equivalent to negative and positive regression coefficients respectively. 
The coherence function, which theoretically can assume values between $O$ and $I$, is not shown but it has extremely low values, below o.oor, throughout the frequency range indicating that very little of the flying activity can be explained in terms of a linear transformation of comfort behaviour. Rather, it indicates that other sources must be contributing to its patterning of occurrence. In other words flying and comfort behaviour are to a large extent statistically independent processes, showing minimal common causations and little interactions, this supporting the contention that comfort behaviour shares little causation with behaviour involving marked activity or arousal.

\section{DISCUSSION}

One of the contributions ethology has made to the study of animal behaviour, has been to stress the necessity of extensive and accurate descriptions of behaviour as premises to explanations of behaviour. This has led to a search for more precise descriptive frameworks starting with the simple qualitative descriptions of early ethologists, followed by the sequence diagrams (e.g., HiNDE, I954) which were then formalized to transition matrices (e.g., ANDREw, 1966) and supplemented by frequency correlation matrices (e.g., STokes, 1962) and ending in the detailed descriptive study of NeLson ( I964) combining all these techniques while adding interval distributions to them. The present study attempts to add to this list yet other formats: correlation functions and as derivations from them, frequency response functions. These may, when applied with sufficient time resolution, replace both the transition and frequency correlation matrices since they contain the same information, while providing a considerable amount of additional information. They have been widely used in the past by statisticians, engineers, geophysicists, econometricians and others. Among biologists neurophysiologists apply them, almost as a matter of routine, when studying the behaviour of neuronal networks in terms of sequences of neuronal spikes (Moore, Perker \& Segundo, I966). But also behaviour students have begun using them as evidenced by the recent paper by WeIss et al. (I966). A related type of analysis, frequency analysis, has of course for some time been advocated as descriptive format for biological systems by various authors (e.g., PRINGLE \& WILson, I952) and since been used by many.

The use of such advanced and complex types of analysis is sometimes criticised on the grounds that as long as the use of simpler methods has not been exhausted the more complex methods only confuse the issues instead of clarifying them. Similarly it is argued that behaviour description 
should be a function of theoretical models, i.e. these models prescribing the convenient descriptive formats. While there can be no doubt that both can be powerful procedures, they entail the risk of leading to descriptions which disregard crucial system properties.

In itself these advanced techniques are usually not capable of directly specifying any particular models, but through giving more detailed information on the properties of the system, they reduce the number of models which might have fitted coarser description. This of course will make models more useful since they will presumably tend to generate more restrictive predictions in contrast to some of the present ethological models, which leave much to be desired in this respect, since they can often accommodate easily what obviously are conflicting results by slight shifts of emphasis.

More specifically and keeping in mind that the analysis in this paper had to be confined to only some of the overt maintenance behaviour patterns of Skylarks, i.e. to only part of the total output of the system disregarding completely its inputs, the results indicate that while patterns showed signs of causal connections the relationships between the patterns are certainly complex and differentiated. Little would be gained from attempting to explain them by postulating unitary causal entities or intervening variables such as a comfort drive and the like. Rather it is likely that the relationships are the result of multiple interactions at and between various levels of the nervous system entailing both activation and inhibition and involving also the causal systems of other functional mechanisms than those of comfort behaviour. Here the occurrence of given behaviour patterns at a given time will depend on the total activation resulting from this set of interaction reaching the coordinating "centers" which directly give rise to the movement patterns which we have considered as behaviour units. I think that perhaps models based on the assumption that each type of behavioural event is followed by specified probability time functions, one for each of the various different behavioural events may be both reasonably realistic as well as theoretically manageable. The instantaneous probabilities derived from these functions interact additively $\left(\mathrm{p}_{\mathrm{r}}=\mathrm{p}_{1}+\left(\mathrm{r}-\mathrm{p}_{1}\right) \mathrm{p}_{2}\right.$ and $\mathrm{p}_{\mathrm{r}}=\mathrm{p}_{1}-$ $\left.\left(\begin{array}{ll}p_{1} & p_{2}\end{array}\right)\right)$ to give rise to the probability of occurrence of a given event at any given instant of time. Intervening hypothetical events with associated probability functions could be incorporated in such model when convenient. Obviously the difficulty of such a model would be in deciding on likely time courses for the probability functions, the more so as this paper suggests that nonmonotonic time courses may be required to cater for the rhythmicities found to affect the occurrence of some behaviour patterns. I shall not investigate these suggestions any further here since it is clear that I do not 
have sufficient information for reasonably proposing such a model ${ }^{1}$ ). This is particularly so due to the lack of clearcut a priori optimality criteria (Rosen, 1967) as are available for other functional systems such as orientation and feeding, where the overall functions of the system is fairly obvious and can be specified. The involvement of maintenance behaviour in displacement activities for example, seems to suggest that some of the pattern fulfill another function than just those obvious ones of e.g. maintaining the body surface (grooming behaviour) or muscles (stretching behaviour) in condition without interfering unduly with other functions. This other function, as I suggest elsewhere (Delius, I967) involve that comfort and some other behaviour are facilitated by a neural system leading to sleep. This contention has found some support in the present paper, but otherwise little can be said as yet about the mechanisms mediating the various interactions.

One of the aims of this paper was to explore the applicability of random signal or event analysis to behaviour and the following comments may be taken as the conclusions in this respect. While doubtlessly some aspects of the analytical techniques could do with further development and clarification, the future problem will be less in finding suitable analytical techniques as they are likely to arise anyway as by-products of man-made hyper complex systems, but more the design of technological hardware enabling us to acquire the information necessary for such advanced analysis. It should be capable of recording the behaviour of unrestrained animals and the stimuli from the environment which are likely to affect it with the necessary degree of accuracy, without involving the subjectiveness of human decisions. In this way we will have information on both the input and output of the system, but it goes without saying that no harm would ensue if such instrumentation would also provide data on internal variables of the system. Generally it seems expedient that as many as possible relevant variables should be recorded. All these informations should be coded in a mode directly accessible to computers, preferably in on-line operation. Samples should be taken over as long a period as feasible with a time resolution as fine as possible. Non-stationariness should be dealt with more carefully than in this paper, either by attempting to reduce it by keeping the environment and the system as invariant as possible, or by tackling it with suitable analytical techniques. More insistence should be placed on estimations of the statistical reliability of the results than I have done here.

I) After writing this, HAuske (1967) has published an admirable paper which explores a model of this type. It is in fact a version of the semi-markov models proposed by CANE (1959). Using an interesting technique he obtains estimated probability time functions by direct analysis of the data. 
Finally, on a less technical line, it would be desirable that more models related to this type of analysis should be explored and more fully so than hitherto.

\section{SUMMARY}

The paper attempts to describe the maintenance behaviour of Skylarks Alauda arvensis using conventional qualitative and quantitative descriptive frameworks and, as a new technique, random event series analysis. It is based on behaviour records of individually marked birds which were observed in the field for extended periods.

Starting from frequency analysis and tising random signal analysis as a stepping stone the rationale of random event analysis is briefly explained. Some of the problems involved in considering behaviour sequences as signals and the implications of viewing animals as black box systems, particularly when only the output i.e. behaviour, is available, are reviewed. The limitations of random event analysis for dealing with non-stationarity and non-linearity are considered.

A qualitative description of the maintenance behaviour follows. Some information is given on the behavioural responses to environmental stimuli, particularly to the arrival of the observer. The sequential organisation of the behaviour in terms of transition probabilities is presented next. Deviations from a null order model are found when the behaviour events are separated by less than a minute and some of the implications are briefly mentioned. In a special subsection the sequential organisation of preening is similarly treated but on the basis of too few data to give any conclusive result. Then the distribution of intervals between the various behaviour patterns are given in a matrix form and some indications of deviations of random occurrence are found and discussed. A matrix of inter-behaviour correlations based on the frequency of behavioural events per various time rnits is presented and the finding that the duration of time units affects the correlations is discussed. In this context some correlation coefficients with non-maintenance behaviour are given and they support the idea that the comfort patterns may be related to a sleep syndrome. Matrices of autoand cross-correlation functions and the related intensity functions support the view that frequency correlation matrices are not capable of imparting information on an important characteristic of interbehaviour relationships, the time dependent dynamic responses. Lastly, the transformation of the correlation function, the auto- and crossspectra, are presented for comfort behaviour and flying. These support the notion that comfort behaviour is affected by rhythmical processes while flying is shown in an essentially random fashion. Little systematic relationship was found between comfort behaviour and flying as reflected by the transfer and coherence functions.

In the discussion the various quantitative descriptive formats are briefly discussed and some of the objections to the use of advanced analytical techniques are dealt with. The implications of these techniques for models of behaviour are discussed and the complexity of interactions between the causal processes leading to behaviour are stressed. Finally some suggestions for future work are offered.

\section{LITERATURE}

Altmann, S. A. (I965). Stochastic model of social commtnication. - J. Theoret. Biol. 8, p. 490-522.

ANDREw, R. J. (1956). Normal and irrelevant toilet behaviour in Emberiza spp. Anim. Behav. 4, p. 85-9I.

Aschoff, J. (Ig6I). Exogenous and endogenous components in circadian rhythms. Cold Spring Harbor Sympos. 25, p. II-28. 
AshroRD, W. (I915). Larks method of gathering food for young. - Brit. Birds, 9, p. I54.

Bartlett, M. S. (Ig66). Introduction to Stochastic Processes. - Cambridge University Press, Cambridge.

Bendat, J. S. \& Piersol, A. G. (1966). Measurement and Analysis of Random Data. Wiley, New York.

Bindra, D. \& Spinner, N. (I958). Response to different degrees of novelty. The incidence of various activities. - J. exp. Anal. Behav. I, p. 34I-350.

CANE, V. (I959). Behaviour sequences as semi-markov chains. - J. Roy. Stat. Soc. B, 2I, p. 36-58.

Caughey, T. K. (1963). In: Random Vibration (ed. S. H. Crandall) vol. 2, p. 66-84. - M.I.T. Press, Cambridge Mass.

Cox, D. R. \& Lewis, P. A. W. (1966). The Statistical Analysis of Series and Events. - Methuen-Wiley, London-New York.

Delius, J. D. (1963). Das Verhalten der Feldlerche. - Z. Tierpsychol. 20, p. 297-348.

- (I965). A population study of Skylarks, Alauda arzensis. - Ibis 107, p. 466-492. (I967). Displacement activities and arousal. - Nature 214, p. 1259-60.

DiLGer, W. C. 1956. Hylocichlid thrushes in captivity with notes on their behaviour. Avic. Mag. 62, p. $183-189$.

Eisner, E. (I963). A quantitative study of parental behaviour in the Bengalese Finch. - Behaviour 20, p. I34-206.

Ewer, R. F. (1967). The behaviour of the African Giant Rat. - Z. Tierpsychol. 24, p. 6-79.

HARRISON, C. J. O. (1965). "Stare-down" in birds and its apparent function. - Ardea I3, p. $57-72$.

Hauske, G. (1967). Stochastische und rhytmische Eigenschaften spontan auftretender Verhaltensweisen von Fischen. - Kybernetik 4, p. 26-36.

Heiligenberg, W. (1963). Ursachen für das Auftreten von Instinktbewegungen bei einem Fisch. - Z. vergl. Psychol. 47, p. 339-380.

HiNDE, R. A. (1954). The courtship and copulation of the Greenfinch (Chloris chloris). - Behaviour 7, p. 207-232.

Iersel, J. J. A. van \& Bol, A. C. A. (1958). Preening of two tern species, a study on displacement activities. - Behaviour 23, p. I-88.

McKinney, F. (1965). The comfort movements of Anatidae. - Behaviour 25, p. I20-220.

Ko, W. H. \& Neuman, M. R. (1967). Implant biotelemetry and microelectronics. Science 56, p. $35 \mathrm{I}-360$.

Lewis, P. A. W. (I967). A computer program for the statistical analysis of series of events. - IBM Syst. J., 5, p. 202-225.

Milsum, J. H. (I966). Biological Control Systems Analysis, -- McGraw Hill, New York.

Moore, G. P., Perkel, D. H. \& Segundo, J. P. (I966). Statistical analysis and functional interpretation of neuronal spike data. - Ann. Rev. Physiol. 28, p. 493-522.

Morris, D. (1956). The feather postures of birds and the problem of the origin of social signals. - Behaviour 9, p. 75-113.

Nerson, K. (1964). The temporal patterning of courtship behaviour in the glandulocaudine fishes. - Behaviour 24, p. 90-146.

Perkel, D. H., Gerstein, G. L. \& Moore, G. P. (I967). Neuronal spike trains and stochastic processes. -- Biophys. J. 7, p. 391-440.

Pringle, J. W. \& Wilson, D. M. (I952). The response of a sense organ to a harmonic stimulus. - J. exp. Biol. 29, p. 220-234.

Rosen, R. (I967). Optimality Principles in Biology. - Butterworth, London.

Scheibel, M. E. \& Scheibel, A. B. (Ig66). Periodic sensory nonresponsiveness in reticular neurons. - Arch. ital. Biol. 103, p. 300-316. 
Schleidr, W. M. (1964). Uther das Wirkungsgefüge von Balzbewegungen des Truthahnes. - Naturwiss. 5I, p. 445-446.

- (1965). Gaussian interval distributions in spontancously occurring innate behaviour. - Nature 206, p. I061-1062.

Stokes, A. W. (I962). Agonistic behaviour among Blue tits at a winter feeding station. - Behaviour I9, p. II8-I38.

TukEY, J. W. (I96I). Discussion emphasizing the connections between analysis of variance and spectrum analysis. - 'Technometrics 3, p. 19I-2I9.

Walter, D. O. (1963). Spectral analysis for electroencephalograms. - Exper. Neurol. 8, p. I55-I8I.

Weiss, B., Laties, V. G., Sieger., L. \& Goldstein, D. (ig66). A computer analysis of serial interactions in spaced responding. - J. exp. Anal. Behav. 9, p. 6Ig-626.

West, G. C. (1965). Shivering and heat production in wild birds. - Physiol. Zool. 38, p. II I-I 20.

ZADEH, L. A. (1957). Signal flow graphs and random signals. - Proc. Inst. Rad. Eng. 45, p. 14I3-I4I4.

\section{ZUSAMMENFASSUNG}

Das nichtreproduktive Verhalten der Feldlerche Alauda arzensis wird in dieser Arbeit sowohl mittels konventioneller qualitativer und quantitativer Methoden, als auch mit Hilfe eines neten analytischen Verfahrens, der Impulsserienanalyse beschrieben. Hierzu wurden ausgedehnte Verhaltensprotokolle von frcilebenden, individuell gekennzeichneten Vögeln benutzt.

Ausgehend von der Frequenzanalyse und unter Benutzung der Signalanalyse als Ubergang, werden die Grundlagen der Impulsserienanalysc kurz erläutert. Finige der Probleme, die sich ergeben, wenn man Verhaltensweisen als Impulsereignisse behandelt und Ticre als Blocksysteme betrachtet, werden genannt, insbesondere wenn nur deren Atssgang, d.h. ihr Verhalten, bekannt ist. Fs wird darauf hingewiesen, daB der Analyse im Falle von nicht-stationären und nicht-linearen Systemen zur Zeit Grenzen gesetzt sind.

Qualitative Beschreibungen der Verhaltensweisen folgen. Verhaltensantworten auf Reizänderung in der Umwelt werden erörtert, besonders solche, die bei Ankunft und Anwesenheit des Beobachters eintreten. Das Aufeinanderfolgen der verschiedenen Verhaltensweisen wird mit Übergangswahrscheinlichkeitstabellen dargestellt. Wenn die Verhaltensweisen innerhalb einer Minute aufeinander folgten, wurden Abweichungen von einem Null-Modell gefunden, deren Ursprung erörtert wird. Das Gefiederputzverhalten wird gesondert in ähnlicher Weise behandelt, aber aufgrund geringen Materials sind keine gesicherten Schlußfolgerungen möglich. Die Abstandsvertcilungen zwischen den verschiedenen Verhaltensereignissen wcrden in einer Matrix gezeigt und dic gefundenen Abweichungen von der Zufallsverteilung besprochen. Korrelationskoeffizienten zwischen den verschiedenen Verhaltensweisen, berechnet an der Häufigkeit mit der sie in verschiedenen langen Zeiteinheiten auftreten, werden als Funktionen dieser Zeiteinheiten in einer Matrix dargestellt. Es stellt sich heraus, daß die Dauer der Einheiten die Korrelationen stark beeinflußt. In diescm Zusammenhang wcrden Korrelationskoeffizienten zwischen Körperpflegeverhalten und anderen Verhaltensweisen erwähnt, die die These unterstützen, daß Körperpflege im Kausalztsammenhang mit Schlaf steht. Auto- und Kreuzkorrelationsfunktionen, als auch die verwandten Erwartungsgrößenfunktionen worden in Matrizes dargestellt und sie bestätigen die Annahme, daß Frequenzkorrelationen nicht fähig sind, eine wichtige Eigenschaft der Zwischenverhaltensbeziehungen aufzuzeigen, nämlich die zeitabhängigen, dynamischen. Zuletzt werden die Umwandlungen der Korrelationsfunktionen, die azto- und kreuzspektralen Funktionen, für Körperpflegeverhalten und Fliegen gezeigt. Sie unter- 